\title{
A TEORIA DAS RELAÇÕES SOCIAIS DE SEXO: um quadro de análise sobre a dominação masculina
}

\author{
Anne-Marie Devreux*
}

\begin{abstract}
Resumo: Este artigo expõe o sistema conceitual elaborado na França, em torno do conceito de relação social de sexo. Mostra as ligações teóricas entre, de um lado, as modalidades de ação ou as atividades dessa relação social, isto é, a divisão sexual do trabalho, a divisão sexual do poder e a produção de categorias de pensamento sexuadas e, de outro lado, as propriedades formais das relações sociais de sexo: seu caráter transversal, sua dinâmica, seu caráter antagônico. Essas propriedades são ilustradas por meio dos resultados de pesquisas de campo efetuadas pela autora na área da família, do trabalho doméstico e da armada ou, ainda, a propósito da sexuação da memória. Igualmente, o artigo explicita a preferência da autora pelo conceito de relação social de sexo, relativamente ao conceito de relação social de gênero.
\end{abstract}

Palavras-chave: relação social de sexo, dominação masculina, categorização de sexo, teoria sociológica, epistemologia.

Este artigo propõe uma construção teórica sociológica: a teoria das relações sociais de sexo, elaborada na França ${ }^{1}$ há pouco mais de vinte anos e para a qual contribuí desde o início. Recentemente, clarifiquei laços lógicos entre diferentes conceitos amplos utilizados no domínio dos estudos sobre as mulheres, o gênero e as relações entre os grupos de sexo.

* Doutora em Sociologia, Pesquisadora HDR (Habilitada a Dirigir Pesquisas) do Centre National de la Recherche Scientifique (CNRS), Paris. Está ligada ao Laboratoire Cultures et Sociétés Urbaines, unidade mista CNRS e Universidade Paris 8.

Este artigo retoma palestra feita em 7 de dezembro de 2004, no Núcleo de Estudos e Pesquisa sobre e Mulher da Universidade de Brasília (NEPeM/UnB).

Traduzido do francês por Ana Liési Thurler.

Artigo recebido em 23 jun. 2005; aprovado em 28 nov. 2005. 
A sociologia das relações sociais de sexo se distingue das teorias de gênero e iniciarei minha exposição por esse ponto, que me parece essencial para se compreender sua importância teórica e prática. Desenvolverei, em seguida, o conteúdo do sistema conceitual das relações sociais de sexo, isto é, seus modos de ação e suas propriedades formais. Em torno desse último ponto, apresentarei algumas ilustrações selecionadas de meus trabalhos empíricos. $\mathrm{Na}$ realidade, o fio condutor de minha pesquisa foi explicitar as propriedades formais das relações sociais de sexo.

\section{Gênero e relações sociais de sexo}

Nos estudos franceses em torno da dominação dos homens sobre as mulheres, gênero e relações sociais de sexo não são conceitos opostos. Freqüentemente são usados como sinônimos, mas, em meu entendimento, se distinguem sob muitos ângulos. Por diversas razões prefiro o conceito de relação social de sexo.

O ponto mais importante reside na acentuação do fato de que as relações entre os homens e as mulheres constituem uma relação social. O gênero diz mais das categorias, da categorização do sexo que, para mim, é o resultado da relação, uma das modalidades pelas quais a relação social entre os sexos se exprime, mas não toda a relação.

No sentido marxista, uma relação social é uma oposição estrutural de duas classes com interesses antagônicos. Com o estudo das relações sociais de sexo assistimos a um enriquecimento do marxismo. Para esse campo de estudos, os sistemas de representação (o domínio do “ideal”, para retomar a expressão de Maurice Godelier, 1984) são tão importantes quanto as práticas da divisão do trabalho e do poder, tão importantes quanto a dimensão material na dominação dos homens sobre as mulheres. Reciprocamente, o material é tão importante quanto o ideal, o que rompe com a concepção exposta por Pierre Bourdieu sobre a dominação masculina (1998). Para ele, no caso da dominação masculina, as formas simbólicas da dominação são preeminentes. A opressão material é admitida, mas deixada fora da análise. Pierre Bourdieu fez das formas simbólicas da dominação a totalidade heurística da dominação masculina (Devreux, 2000). 
Uma segunda razão leva-me a preferir o conceito de relação social de sexo ao de gênero: o primeiro nomeia explicitamente o sexo enquanto o segundo termo evita mencioná-lo e o eufemiza. Ora, a referência ao sexo biológico parece-me essencial pois a classificação social dos indivíduos, desde o nascimento, é operada sob esse critério ou, mais precisamente, sob a representação social segundo a qual esse critério é de uma importância primordial para classificar os indivíduos. Psicólogas francesas feministas (Hurtig \& Pichevin, 1986) demonstraram que classificar e definir os indivíduos no nascimento pelo critério da ausência ou da presença do pênis constitui um ato social: essa redução da identidade social ao pênis (ou não) é um ato social. ${ }^{2}$ Cada nascimento dá lugar a esse sintético e fundamental ato social. Fundamental para cada indivíduo e seu futuro, pois a partir desse ato de classificação, sua trajetória começa sob o signo da diferença e da hierarquia.

A socióloga feminista Christine Delphy (2001) falou do pênis como de um "marcador" da divisão social: portanto, o gênero precede o sexo, ${ }^{3}$ deduz ela do fato de que as categorias de classificação pré-existem à importância real do sexo, pré-existem a cada marcação individual. Concordo com ela. Considero, entretanto, mais claro dizer que a relação social constrói-se em torno desse marcador do sexo e, finalmente, que o sexo é primordial, como representação operadora dessa classificação.

Do mesmo modo, prefiro falar em relações sociais de raça para nomear o caráter trivial, "grosseiro" e brutal dessas relações que também hierarquizam os indivíduos com base na cor da pele (outro marcador da divisão social entre os indivíduos), mais do que falar em relações interétnicas (como se pode encontrar mais e mais freqüentemente na França). Na verdade, essa expressão mascara o ódio, a brutalidade e a superioridade da idéia que o branco faz de si mesmo em relação ao não-branco. De certo modo pode-se dizer que o "branco" da pele é o "pênis" da raça: somos brancos ou não-brancos. Somos machos ou não-machos. Pode-se pensar na repulsa dos machos aos não-machos. Por vezes, segundo eles, os homossexuais ou os transexuais. 
Uma terceira razão leva-me a preferir o conceito "relação social de sexo" ao de "gênero". Em francês a palavra "gênero" é polissêmica. Recobre uma definição vaga, incerta do conceito, segundo os pesquisadores ou segundo os atores, ou instituições que a empregam. Algumas vezes, é o sexo do registro de nascimento (o problema existe principalmente em inglês), outras vezes é o gênero gramatical e, outras vezes ainda, a categorização social. Em francês a palavra "gênero" possibilita que evitemos pronunciar a palavra sexo e de fazer referência ao "sexo" (sex, em inglês), à sexualidade. A sexualidade e o campo das relações sexuais fazem parte do problema das relações sociais de sexo, mas não constituem a totalidade do problema.

Penso que a utilização do conceito de "gênero" permitiu às pesquisadoras francesas serem percebidas como menos agressivas, menos "feministas", por suas instituições e por seus colegas homens. Não chocando, elas pensavam chegar mais facilmente a um consenso científico sobre a questão da dominação masculina, mantendo-se mais politicamente corretas. De certa maneira, elas eram mais "polidas", não nomeando nem a violência e o antagonismo contidos na idéia de "relação social", nem o critério um pouco animal de "sexo". É também o que permitiu, em minha interpretação, que pesquisadores homens ingressassem nesta área de pesquisa científica, tornada, assim, mais consensual. Porque, um pouco como ocorre com o termo "condição feminina", o termo "gênero" evoca a idéia de um problema social sofrido pelas mulheres, de uma desigualdade social construída, mas na qual os homens não seriam atores. Incluídos na construção de gênero e defendendo sua situação, classificados como gênero masculino apesar deles, nada teriam a ver com os efeitos dessa classificação. A relação social de sexo nomeia explicitamente a confrontação entre duas classes de sexo. Não pode haver relação social com uma categoria única. Não pode haver relação social sem confrontação.

Uma vez colocadas essas preliminares terminológicas, como fazer funcionar esse conceito de relação social de sexo na análise sociológica?

E por que falar em relações sociais de sexo no plural e, outras vezes, em relação social de sexo no singular? Na França, no 
desenvolvimento do pensamento sociológico feminista, a expressão surgiu no plural. Focalizemos, então, a "variabilidade" das relações sociais de sexo, o caráter variável das formas que elas assumem. Tratava-se de designar o fato de que essas relações não se limitavam a uma só esfera, à esfera da família, por exemplo, nem às relações homens/mulheres no âmbito do casal conjugal. Tratava-se de falar das formas diversas assumidas por essas relações, das formas materiais na exploração do trabalho das mulheres, por exemplo, e das formas simbólicas de opressão ligadas à definição de imagens negativas da mulher e de suas atividades. Assim apreendidas, as relações sociais de sexo recobrem, então, todos os fenômenos de opressão, de exploração e de subordinação das mulheres aos homens. E é essa quantidade de formas e de fenômenos que se oferece como realidade à observação sociológica.

O conceito de "relação social de sexo" se firmou pouco a pouco como uma ferramenta de análise, representando a síntese teórica dessas múltiplas dimensões da dominação masculina. No singular, é uma representação científica que traduz a unicidade da lógica da organização do social que constitui essa dominação das mulheres pelos homens e a irredutibilidade dessa dominação a outra relação social.

Consagrei meu programa de pesquisa à construção de um quadro teórico que permitisse apreender essa lógica social complexa, decompondo o conceito de relação social de sexo em subcategorias de análise, tornando-o mais operacional. Se a pesquisa francesa no domínio do gênero e das relações sociais de sexo foi construída freqüentemente em colaboração com pesquisadoras organizadas em redes, essa perspectiva propriamente teórica é um feito de um número restrito de pesquisadoras. É necessário acumular um grande número de resultados empíricos, de conclusões de pesquisas de campo e de comparações, internacionais ou entre homens e mulheres, para poder começar a construir categorias de análise válidas para confrontações de resultados.

A construção do sistema conceitual que agora proponho decorre de trabalhos comparativos e dessas confrontações. É fruto de um 
longo caminho teórico destinado a fundar a definição de categorias intermediárias de pensamento para apreender as relações sociais de sexo na complexidade do funcionamento social - e apesar dessa complexidade -, particularmente apesar da dificuldade que representa a articulação das relações sociais de sexo com as relações de classe, de raça ou de idade.

A primeira grande relação sistêmica que proponho é a que existe entre as atividades das relações sociais de sexo e suas propriedades formais. As primeiras são as modalidades de ação pelas quais essas relações se exprimem: a divisão sexual do trabalho, a divisão sexual do poder e a categorização do sexo - ou a divisão das categorias do pensamento sobre os sexos. As segundas, as propriedades, são as características formais sob as quais essas relações aparecem no espaço social, por meio do partilhamento desse espaço em esferas ou campos, como a esfera do trabalho produtivo, da família, da escola, do político, etc. Trata-se do caráter transversal (a transversalidade), do caráter dinâmico e do caráter antagônico das relações sociais de sexo, sobre os quais retornarei.

Todas essas categorias de análise - atividades, divisão sexual do trabalho ou do poder, categorização, propriedades formais, transversalidade, dinâmica, antagonismo - não mudam fundamentalmente nada relativamente ao funcionamento das relações sociais de sexo. Representam a decomposição teórica desse funcionamento, permitindo a apreensão desse funcionamento, possibilitam o conhecimento dele, a tomada de consciência e, assim, podem tornar-se instrumento de mudança. Portanto, são categorias cognitivas e, como tal, instrumentos de mudança social.

\section{As atividades das relações sociais de sexo}

$\mathrm{Na}$ França, relações sociais de sexo e divisão sexual do trabalho foram, por muito tempo, conceitos assimilados a ponto de se recobrirem totalmente e serem quase sinônimos, ou, ao menos, de terem a mesma capacidade de englobar todos os fenômenos sociais 
ligados à dominação dos homens sobre as mulheres (Kergoat, 2000). Por outro lado, as feministas historiadoras ou as cientistas políticas tendiam a colocar, além dessa divisão sexual do trabalho, a questão do compartilhamento do poder entre os sexos ou, mais precisamente, da exclusão das mulheres das esferas do poder e da decisão. Aliás, conforme os objetos de estudo, a opressão ideológica e a inferiorização simbólica dos valores ligados às atividades femininas passaram a ser os valores primeiramente invocados na explicação dos fenômenos de reprodução das desigualdades entre os sexos.

Meus trabalhos sobre trajetórias familiares e profissionais de homens e mulheres, assim como minhas pesquisas sobre a socialização dos meninos e sua aprendizagem sobre a dominação masculina, levaram-me a renunciar a toda hierarquização dessas diferentes expressões das relações sociais de sexo e a concluir, no atual estágio dos conhecimentos em Sociologia, que a divisão sexual do trabalho, a divisão sexual do poder e a categorização do sexo podem ser tidas como as três atividades, as três modalidades de expressão das relações sociais de sexo, sem que seja possível dizer que uma delas, em todas as esferas e em todos os momentos de desenvolvimento de uma sociedade, tem precedência sobre as outras duas. As relações sociais de sexo exprimem-se simultânea e conjuntamente por essas três modalidades. Só o ponto de vista da pesquisa (ou o ângulo de aproximação dos objetos que construímos) muda. Essas três modalidades de divisão e de hierarquização dos homens e das mulheres, de sua atividade de trabalho, de seu poder e dos valores ligados a ambos constituem a relação social de sexo ela mesma, propriamente falando. Conjuntamente, essas três modalidades constituem a relação social de sexo.

A divisão sexual do trabalho, à qual certas análises tendem a reduzir as relações sociais de sexo, é uma divisão social: a organização social do compartilhamento do trabalho (e, portanto, também, do emprego) entre os dois grupos de sexo. Essa divisão sexual do trabalho atravessa toda a sociedade e articula os campos do trabalho produtivo e do trabalho reprodutivo. Não os separa: ela os articula excluindo ou integrando, segundo os momentos e as necessidades dos dominantes, 
as mulheres à esfera produtiva, devolvendo-as global ou parcialmente à esfera reprodutiva. $\mathrm{O}$ trabalho reprodutivo, cujo reconhecimento como trabalho é resultado de longas pesquisas feministas, diz respeito não somente ao trabalho doméstico propriamente dito, mas, também, ao trabalho parental e a todas as tarefas de cuidados e de assumir responsabilidades pelas pessoas (trata-se do care anglo-saxão).

A divisão sexual do poder é transversal pois, também ela, integra a relação social de sexo, conjuntamente com a divisão sexual do trabalho e a categorização do sexo. A pesquisa feminista mostrou que a repartição dos poderes entre os sexos não resultava de processos naturais ligados a capacidades físicas dos homens e das mulheres. Trabalhos sobre política, de um lado, e sobre violência, de outro lado, alimentaram uma reflexão sobre o sexo do poder e desvelaram mecanismos pelos quais os homens fundam a natureza do poder na divisão das funções produtivas (exercidas na esfera do trabalho) e reprodutivas (exercidas na esfera da família). Assim, a divisão sexual do poder apóia-se tanto sobre a divisão sexual do trabalho quanto sobre a categorização, isto é, a definição das categorias ligadas à sexuação social. Por exemplo, a cidadania respectiva dos homens e das mulheres, isto é, seus direitos e seus deveres perante a comunidade nacional, é definida em função do lugar que eles e elas, supostamente, ocupam na esfera do trabalho e na família. Em outras palavras, também no corte que a sociedade instaura entre o domínio do público e o domínio do privado.

A categorização é um terceiro modo de ação das relações sociais de sexo que se exerce conjuntamente com os dois primeiros. Cada vez que há divisão sexual do trabalho ou do poder, há criação e reiteração de categorizações sexuadas. A primeira das grandes categorizações sociais de sexo concerne, evidentemente, à partição dos indivíduos entre categorias de sexo, entre "homens" e "mulheres". Seguiu-se toda uma visão do mundo organizada em um sistema de atributos, de normas, de valores, etc., fixando uma oposição entre o "masculino" e o "feminino". Por exemplo, o trabalho parental efetuado pelas mulheres, em nome de sua função biológica na reprodução da vida humana, há muito tempo foi qualificado como "função maternal", 
sem que haja um equivalente masculino. Assim, a parentalidade, ligada ao fato parental de assumir a responsabilidade material das crianças, não adviria do domínio do social, mas derivaria da natureza maternal das mulheres.

Esse trabalho de categorização operado por meio das relações sociais de sexo consiste em dar - e fixar como verdade definições sociais: estabelecer o que é um homem e o que é uma mulher; estabelecer o que é trabalho e o que não o é; o que é produção e o que não o é. Estabelecer, também, o que é normal para uma mulher e o que não o é; estabelecer o que é possível para uma mulher e o que não o é; estabelecer o que é socialmente aceitável e o que é desvalorizável, etc. Tal trabalho de categorização é assimétrico: a posição dominante dos homens dispensa estabelecer o que é o masculino, pois o masculino é a norma de referência. É necessário, para essa dominação masculina, ditar o que não é suficientemente viril (por exemplo, com relação à homossexualidade) para consolidar a norma de referência.

Essas três atividades são, portanto, uma decomposição do conceito de relação social de sexo e correspondem, na análise, a privilegiados pontos de vista. Como vimos anteriormente, para certas pesquisadoras, a divisão sexual do trabalho constitui a relação social de sexo e de poder, sendo as categorias de sexo decorrente dessa primeira estruturação do social. Assim, o poder seria a conseqüência da divisão sexual do trabalho produtivo e reprodutivo. Pessoalmente, considero que tal concepção pode corresponder a certos momentos, a certos estados das relações sociais de sexo, mas pode também bloquear o pensamento, uma vez que, a priori, foi decidida uma tal hierarquização entre as expressões das relações sociais de sexo. Parece-me que isso impede a utilização da teoria das relações sociais de sexo em outras sociedades, além daquelas sociedades onde o trabalho assalariado é o motor de partições sociais. Por exemplo, o trabalho de categorização, isto é, a atividade simbólica das relações sociais de sexo, a atividade de classificação hierarquizada entre homens e mulheres e seus respectivos atributos, parece-me, às vezes, mais importante do que a divisão sexual do trabalho como mecanismo 
das relações sociais de sexo. No Afeganistão, esconder as mulheres sob o chador e matá-las se uma mecha de seus cabelos ficar à mostra, quer dizer: "esta mulher vale somente como propriedade de um homem, mesmo que ela nada faça como trabalho”.

A teoria das relações sociais de sexo, como a apresento, pretende ter um alcance heurístico universal na decifração dos fatos sociais relativos à opressão das mulheres, ou seja, à dominação dos homens sobre as mulheres.

\section{As propriedades formais das relações sociais de sexo}

Em referência à realidade das expressões de relações sociais de sexo, que são as atividades de divisão e de categorização explicitadas anteriormente, as propriedades formais constituem uma representação científica que visa permitir balizar o funcionamento específico dessas relações no emaranhado de fatos sociais e, notadamente, de apreender sua evolução.

\section{A transversalidade das relações sociais de sexo}

A primeira dessas propriedades foi posta em evidência graças às pesquisas sobre as articulações entre sistema produtivo e esfera familiar (Le sexe du travail, 1984). Ela diz respeito à transversalidade das relações sociais de sexo. Essa propriedade indica, ao mesmo tempo, que se pode encontrar essas relações em ação por toda parte na sociedade e que sua lógica coloca em relação ou "articula" todos os campos da sociedade. Por exemplo, ela coloca em relação o trabalho profissional e a família, o trabalho profissional e a saúde, a política e o trabalho, a política e a família, e mesmo a política e as articulações entre trabalho e família, ou ainda, o exército e a família, etc.

Essas relações podem operar "por toda parte", significando isso que se pode descobri-las agindo mesmo lá onde somente uma 
categoria de sexo está fisicamente representada. Em pesquisa com homens convocados para o serviço militar (quando o recrutamento não havia ainda sido suprimido na França), demonstrei que as relações de sexo operavam na divisão do trabalho, na repartição dos poderes e nos processos de categorização, mesmo que as mulheres estivessem fisicamente ausentes da esfera militar (Devreux, 1992, 1997). As relações sociais de sexo podem também agir em ambientes exclusivamente masculinos. A descoberta dessa característica das relações sociais de sexo permitiu romper com a idéia de que essas relações dizem respeito somente, ou sobretudo, às relações entre os homens e as mulheres no seio da família ou, pior, no âmbito do casal conjugal.

A idéia de transversalidade das relações sociais de sexo se impôs, entretanto, após um conjunto de trabalhos sobre as articulações entre a função dita reprodutiva e a função produtiva das mulheres. Parti da hipótese de que, em uma sociedade como a sociedade francesa, que dispõe dos meios de controle dos nascimentos, não se poderia compreender as escolhas das mulheres em matéria de fecundidade (número de crianças, momento dos nascimentos, espaçamento entre os nascimentos, etc.), se não se estudasse simultaneamente seu estatuto sob o olhar do mundo do trabalho e, eventualmente, seu lugar nesse mundo.

A sociedade francesa é uma sociedade relativamente livre do ponto de vista do acesso à contracepção e ao aborto. As decisões individuais em matéria de fecundidade são determinantes do nível de natalidade. Até o final dos anos 70, os especialistas das ciências sociais associaram a questão da redução da natalidade ao fato de as mulheres, decidindo se inserir no mercado de trabalho, colocarem em risco o nível de sua fecundidade e, por conseqüência, a reprodução da sociedade. Era a época em que os poderes públicos buscavam diversas fórmulas atraentes para manter as mulheres em casa e conseguir que elas produzissem o famoso terceiro filho, que garantia a renovação das gerações. Era um ponto de vista que considerava o trabalho profissional das mulheres na dimensão de uma atividade e não seu conteúdo real: trabalhando as mulheres estavam, sobretudo, 
ausentes de casa. Era como se o seu trabalho profissional não tivesse conteúdo, nem condições materiais ou financeiras de execução, nem sentido ou interesse próprio para as mulheres.

Entrevistas com mulheres ativas e mães de família confirmaram que a vida profissional das mulheres e seu ambiente de trabalho têm, ao contrário, importância capital na determinação do tamanho de sua descendência e, portanto, sobre sua fecundidade. As condições oferecidas à maternidade no trabalho (Devreux, 1986) desempenham um papel na decisão de ter ou não um filho. Desde que as mulheres quiseram trabalhar, a participação na produção passou a ser para elas garantia identitária - para além de ter uma profissão e para além do peso econômico -, e a escolha da maternidade tornou-se dependente das condições da vida profissional delas. Minhas pesquisas, desenvolvidas junto a mulheres de diferentes categorias socioprofissionais e em diversos ambientes de trabalho, mostraram que a produção da vida humana é muito mal integrada à produção de bens e serviços, a despeito de a sociedade francesa se dizer muito protetora da maternidade e do nascimento. Salvo em certos ambientes de trabalho muito feminilizados, nos quais a maternidade contribui para relações de solidariedade com as mulheres grávidas, a maioria das mulheres sofre muito fortemente a contradição estrutural entre sua função reprodutora e sua função produtora. As mulheres de níveis superiores, que estão em postos de forte responsabilidade, retardarão suas maternidades e, algumas vezes, decidirão, finalmente, por um número de filhos inferior ao que teriam desejado. As operárias não terão outra solução para levar sua gravidez a termo do que sair da produção. Quando as condições para a guarda de seus filhos se tornam excessivamente difíceis e onerosas, elas caem em empregos precários e com horários flexíveis para compatibilizar um lugar no mercado de trabalho e o desempenho de suas funções maternais. Umas são desestabilizadas em seu projeto reprodutivo; as outras, em sua função produtiva.

Pesquisas que desenvolvi junto a pais mostraram que, para os homens, ao contrário, a paternidade, geralmente, fortalece seu estatuto profissional. Segundo estudos estatísticos (Fermanian \& Lagarde, 
1998), mais eles têm filhos, mais investem no domínio profissional e se ausentam da vida familiar, deixando de assumir a responsabilidade material, real, dos filhos e melhorando seu estatuto profissional. Nos relatos de vida de pais que entrevistei, constatei, também, que a minoria dos homens que verdadeiramente partilhava com as mães o trabalho educativo e os cuidados com os filhos apresentava a tendência de ter uma trajetória profissional que se aproximava da trajetória das mulheres mães e ativas: por exemplo, eles sofriam atrasos nas carreiras, relativamente a outros homens, eram excluídos de horários suplementares e tinham suas remunerações menores do que as remunerações dos homens que não participavam, na vida cotidiana, da educação de suas crianças.

A propósito das articulações entre a trajetória profissional e a trajetória familiar, demonstrei que a divisão sexual do trabalho opera de maneira transversal nos domínios do trabalho e da família. Confrontando esses resultados com os de outras pesquisadoras, foi possível demonstrar que todos os domínios da sociedade são atingidos pela transversalidade das relações sociais de sexo. Foi a razão pela qual pesquisei, a seguir, como se articulam as trajetórias familiar, amorosa, escolar e pré-profissional com a experiência do serviço militar no processo de socialização dos meninos pelo exército, com o alistamento militar. Retomarei mais adiante aos resultados desse estudo.

\section{A dinâmica das relações sociais de sexo}

A importância da questão da dinâmica própria das relações sociais de sexo surgiu quando foi colocada a interrogação sobre a reprodução social e a dinâmica das hierarquias entre os sexos na mudança social. Em Sociologia, a idéia de reprodução social recobre, freqüentemente, a idéia de uma reprodução do idêntico, enquanto a mudança social é mais freqüentemente percebida em sua dimensão de progresso social. Ora, a mudança social pode se dar tanto no sentido do progresso, quanto no sentido da regressão social. No 
funcionamento de uma relação social, o sentido de mudança não pode ser apresentado antecipadamente, pois ela é resultado da relação de força entre os dois grupos envolvidos.

Relativamente à dominação masculina, sociólogos não feministas - e algumas vezes até feministas - freqüentemente pensam ser a melhoria da situação das mulheres o único processo de mudança digno de interesse. Entretanto, numerosos fenômenos de regressão social com referência à mulher, por toda parte no planeta, são, periodicamente, constatados por meio das observações sociológicas - ainda que a interpretação desses resultados não ocorra no sentido do consenso social, mesmo em países desenvolvidos como a França. É necessário, portanto, que a pesquisa feminista em ciências sociais trabalhe nos dois sentidos: no estudo do progresso social e no estudo da regressão social no que diz respeito à situação das mulheres.

Falar da dinâmica das relações sociais de sexo implica que essas relações se desenvolvem segundo sua própria lógica, mesmo que essa lógica esteja em interação com aquelas de outras relações sociais, sejam de classe, de raça ou de geração. Isso significa que elas não evoluem somente porque a relação capital e trabalho se modificava, como durante muito tempo os marxistas supunham. $\mathrm{O}$ progresso social em favor das classes trabalhadoras não significa, automaticamente, o progresso em favor das mulheres, enquanto mulheres dominadas pelos homens: a degradação do mercado de trabalho, por exemplo, freqüentemente conduz a uma degradação acentuada no nível de emprego para as mulheres, pelas desigualdades de sexo e pela inferiorização social das mulheres.

Coloco em evidência, particularmente, o caráter dinâmico das relações sociais de sexo, o caráter moderador ou impulsionador da mudança, por meio de um estudo sobre o trabalho da memória em relatos biográficos de homens e de mulheres. Trata-se de análise secundária do material das investigações sobre maternidade e paternidade que mencionei anteriormente. Quando realizei essa pesquisa sobre a memória, ela constituía objeto de estudo original na Sociologia francesa. Até então, a memória era um tanto o domínio reservado dos historiadores, particularmente dos historiadores usando 
fontes orais. Em Sociologia, Maurice Halbwachs (1925) abriu um caminho, mostrando que os determinantes do funcionamento da memória são sociais: situam-se nas experiências vividas no presente, que dão a essa memória seus "quadros sociais".

Esses materiais de pesquisa abordam a experiência do trabalho doméstico e parental entre homens e mulheres, eles mesmos pais, mas também filhos e filhas de seus próprios pais e mães. Se todas as mulheres entrevistadas realizam o trabalho educativo e de cuidados com os filhos, no grupo dos homens pode-se distinguir os homens que participam dessas tarefas daqueles que são, material e concretamente, descomprometidos.

Comparando, por um lado, os homens e as mulheres e, de outra parte, o grupo dos homens participantes das tarefas domésticas e parentais com os homens não participantes, foi possível revelar fortes diferenças no modo pelos quais esses homens e essas mulheres rememoravam, no decorrer de suas próprias infâncias, o trabalho que seus próprios pais e mães realizavam.

Assim, os homens que realizam hoje o trabalho doméstico e parental tendem a se aproximar do grupo das mulheres à medida que são muito mais capazes de colocar em cena, na exposição de suas lembranças, o trabalho realizado por suas mães no interior de sua família de origem. Ao contrário, os homens hoje distanciados das contingências materiais da vida doméstica e dos cuidados com os filhos valorizam a figura paterna nas lembranças de sua família de origem, omitindo-se de falar em sua mãe ou minorando visivelmente sua atividade: "Minha mãe? Ah, ela não trabalhava". Entretanto, recompondo os elementos de sua família de origem na continuidade da entrevista, constatava-se que a mãe desses homens, por um lado, efetuava todo o trabalho doméstico da casa e, por outro lado, exercia uma atividade profissional sob os olhos mesmo da criança que agora era nosso entrevistado, sendo a cuidadora das crianças no domicílio. Ao contrário, quanto mais o pai desses homens estava ausente da família pelo fato de seu super-investimento na esfera profissional (horas suplementares, retornos tardios à casa), mais os filhos colocam- 
no hoje em um pedestal simbólico, transformam-no em uma figura mítica de uma autoridade superior, sendo o apoio para seu poder precisamente a distância dos problemas materiais cotidianos da educação das crianças.

Concluí ser a atividade doméstica presente dos indivíduos que os torna capazes de rememorar o trabalho doméstico realizado por sua mãe, em sua infância. Esse resultado é tal que os homens que hoje realizam tarefas domésticas adotam, para falar sobre isso, o mesmo ritmo da palavra das mulheres. Um ritmo de discurso que encadeia verbos de ação, descrevendo a sucessão rápida das tarefas do trabalho doméstico, em particular quando se trata de se ocupar com as crianças: um discurso impregnado de referências concretas, colado à materialidade das ações, enquanto os pais hoje nãoparticipantes evocam sua paternidade e a de seu próprio pai em termos muito generosos, "filosofando" sobre a função paterna e sua importância na ordem familiar e social. Os quadros da memória não são somente sociais. São também sexuados: eles são sociossexuados (Devreux, 1985).

Do ponto de vista da questão da dinâmica das relações sociais de sexo, essa pesquisa ilustrou um dos caminhos pelos quais se reproduzem as representações dos lugares ocupados por homens e mulheres na divisão sexual do trabalho doméstico (e profissional). Ela permitiu compreender como se reproduzem ou se transformam as formas ideais das relações sociais de sexo e como esse processo acompanha a mudança ou o imobilismo das práticas sociais.

Como se vê nesta rápida síntese, esta reflexão sobre a memória ilustrou também o funcionamento da divisão sexual do trabalho, do poder patriarcal na família e, enfim, da produção dos valores ligados a atividades dos homens e das mulheres, isto é, do trabalho de categorização operado pelas relações sociais de sexo.

\section{O antagonismo das relações sociais de sexo}

O antagonismo das relações sociais de sexo constitui uma terceira propriedade dessas relações. No que concerne às relações 
entre homens e mulheres, não é fácil admitir a idéia de um antagonismo de classe. Com efeito, essa hipótese sugere que os grupos de sexo se opõem por interesses radicalmente contrários, mesmo que as relações homens/mulheres mais visíveis são feitas de amor, em todo caso, no interior da família. Mais ainda, essas relações de amor subentendem uma solidariedade conjugal que permite a realização de projetos comuns, no sentido oposto do antagonismo de interesses, tais como: a educação dos filhos, a aquisição de uma casa, etc...

Foi a demonstração da opressão das mulheres no interior do casamento (Delphy, 1970, 1998) que conduziu à idéia de antagonismo. Como classe trabalhando gratuitamente para a reprodução da célula familiar, as mulheres vêem seu trabalho explorado pelo conjunto dos homens, os quais agem no sentido da reprodução dessa divisão do trabalho. No ponto de partida da análise das relações homens/ mulheres, em termos de relações sociais de sexo, encontra-se o postulado do antagonismo. De um ponto de vista teórico, uma relação social supõe o antagonismo entre os dois grupos, as duas classes que ela opõe. Sem divergência radical, sem oposição dos interesses respectivos dessas duas classes, simplesmente não há espaço para se falar em relação social.

Os resultados empíricos das pesquisas sobre a situação social das mulheres mostram claramente que, do ponto de vista do devir da dominação de sexo, os interesses dos homens e das mulheres opõemse radicalmente. Eles lutam para preservar os benefícios obtidos com a dominação sobre as mulheres e a exploração do trabalho delas. Elas lutam para se desembaraçar dessa opressão e reduzir os efeitos dela sobre suas condições de vida, sobre sua liberdade e sobre sua integridade física.

É importante registrar a necessidade do pensamento utópico (Riot-Sarcey, 1998) no estudo das relações homens/mulheres em termos de relações sociais de sexo: o antagonismo é tanto a expressão de uma luta, de uma relação de força, quanto, teoricamente, está destinado a desaparecer com o desaparecimento da opressão que aí está em jogo. O horizonte utópico da luta das mulheres não é o 
desaparecimento dos homens (como pretendem caricaturas do pensamento feminista, com a famosa idéia de "guerra dos sexos", na qual, freqüentemente, somente as mulheres parecem ser o braço armado, mesmo que a violência de sexo, muitas vezes letal, seja o fato dominante), mas o desaparecimento da opressão de um grupo social (o grupo dos homens) sobre um outro grupo social (o grupo das mulheres).

A noção de antagonismo permite pensar em incluir na reflexão a dimensão de luta caracterizando a relação social de sexo. Essa noção revela uma dimensão freqüentemente ocultada: os homens também lutam nessa relação social. Lutam às vezes violentamente para preservar seus interesses de sexo. A urgência científica, devida ao longo silêncio que ocultou a questão do lugar social das mulheres - tanto na História quanto na Sociologia, na Economia e nas Ciências Políticas -, fez com que os primeiros trabalhos sobre os sexos fossem dedicados à caracterização da inferioridade das mulheres e à pesquisa das causas dessa inferiorização, em todos os espaços da sociedade. Desse fato, a dominação masculina tornou-se a dominação das mulheres... Por quem? A resposta ora foi global (pela "sociedade"), ora ocultada pela referência a supostos handicaps naturais das mulheres, como a maternidade.

O recurso à noção de antagonismo não nega a existência de outros antagonismos sociais, entre raças e entre classes sociais. Permite, entretanto, compreender a luta específica das mulheres e, sobretudo, a luta específica dos homens e suas resistências à mudança social em favor das mulheres.

Assim, o foco sobre o princípio do antagonismo levou-me a construir um programa de pesquisa sobre os homens considerados como os atores dessa dominação das mulheres, por conseqüência, um programa de pesquisa dos homens como dominantes.

Uma pesquisa sobre a socialização dos jovens homens no exército, na oportunidade do serviço militar, ${ }^{4}$ possibilitou, primeiro, mostrar como a aprendizagem da dominação masculina se apoiava 
na transmissão do desprezo e do ódio às mulheres pelos graduados, pelos homens adultos aos jovens convocados. Essa transmissão, esse ensinamento dos valores masculinos vinculados a clivagens de sexo, operava-se em todos os momentos da vida militar. A análise do material da pesquisa evidenciou, particularmente, que os momentos fortes dessa transmissão ocorriam no manuseio das armas, ou seja, envolvendo o atributo mesmo do estatuto do militar. Por exemplo, os jovens alistados aprendiam com os adultos graduados que seu fuzil deveria ser vigiado "como sua mulher" e sempre mantido sob os olhos, sob pena de virem a ser derrubados por um inimigo, representando o rival, esse homem capaz de, a qualquer momento, apoderar-se de sua propriedade. Nessa aprendizagem, as mulheres eram desumanizadas e, claramente, tratadas como objetos. Aliás, os trabalhos domésticos necessários para a manutenção dos locais militares eram oportunidade de aprendizagem da divisão sexual do trabalho, pela qual se pretendia serem essas tarefas invisíveis e desvalorizadas, devendo ser realizadas de forma repetitiva e sem reconhecimento por seus beneficiários. $\mathrm{O}$ uso dessas obrigações domésticas pelos graduados para definir as relações hierárquicas e atestar o poder dos mais poderosos servia de vetor ao ensinamento da divisão sexual do trabalho na família e dos valores sociais ligados às tarefas realizadas habitualmente pelas mulheres fora da vida militar. Aliás, no retorno a suas casas, os rapazes se distanciavam o mais possível dessas tarefas, delegando-as à sua mãe ou à sua companheira (Devreux, 1997, 2002).

Mais recentemente prossegui meu programa de estudo sobre os homens como dominantes com a análise das mudanças na divisão do trabalho no interior da família, a partir da questão da participação concreta dos homens no trabalho doméstico e parental. Após, liguei os resultados desse estudo à análise dos argumentos dos grupos de defesa dos pais divorciados em favor da igualdade dos direitos parentais. A noção de co-parentalidade, proposta por esses grupos masculinos, inclui a idéia de que os encargos ligados à educação e aos cuidados com os filhos, supostamente, são atualmente assumidos tanto pelos pais, quanto pelas mães. Os dados sobre o uso do tempo 
permitem demonstrar claramente que, entre casais - casados ou não - a repartição do trabalho parental e doméstico ligado à presença dos filhos está longe de ser igual. Tendencialmente, as mulheres ainda fazem o dobro do trabalho doméstico do que o realizado pelos homens. Com filhos pequenos, os pais franceses, em média, não assumem mais do que uma quarta parte do trabalho parental, isto é, o conjunto de tarefas envolvendo cuidar dos filhos, acompanhar o trabalho escolar em casa, brincar com eles, transportá-los para as diversas atividades extra-escolares. Estamos, portanto, distantes de uma co-parentalidade no sentido estrito e de uma igualdade de assumir as responsabilidades dos filhos pelos homens e pelas mulheres. Mesmo nas famílias monoparentais, observa-se que pais vivendo sozinhos com seus filhos - casos raros na França - realizam menos trabalhos domésticos do que as mulheres em idêntica situação. Pode-se deduzir disso que, com a separação do casal, subsiste uma certa desigualdade quanto a assumir responsabilidades pelos filhos e que "viver só com um filho" não tem a mesma significação prática para um homem e para uma mulher.

A "nova paternidade" é na França (e em outros países desenvolvidos, McMahon, 1999) mais uma representação social do que uma realidade prática, porquanto a dupla jornada de trabalho permanece uma restrição concreta pesando fortemente sobre a vida das mulheres e sobre sua carreira profissional. As tendências descritas anteriormente, relativamente à lentidão das mudanças em assumir responsabilidades materiais concretas na vida familiar pelos homens, ocorrem em um contexto em que as mulheres, mais e mais, vêm assumindo uma vida profissional. Foi, então, proposta uma política familiar instituindo uma licença parental, com o que, há uma década, a taxa de atividade feminina começou a baixar. Ainda que neutra do ponto de vista do sexo, essa iniciativa governamental, permitindo, em princípio, tanto ao pai quanto à mãe suspender sua atividade profissional para criar um filho de menos de três anos, revelou-se uma política de gestão do emprego feminino particularmente eficaz e desigual, pois, na realidade, os "beneficiários" dessa licença parental são $99 \%$ mulheres. 
Como se vê, tudo contribui para a reprodução da divisão sexual do trabalho na família. Nesse contexto, a reivindicação dos homens à igualdade dos direitos parentais com referência à autoridade parental sobre os filhos e sobre a guarda deles após o divórcio surge como exigência de concessão de direitos, independente de deveres a que estão ligados. Essa exigência é a expressão de uma relação de força contra as mulheres mais do que uma prova de defesa dos interesses da criança, como anunciam esses grupos masculinos. $\mathrm{O}$ compartilhamento da autoridade parental sobre a criança, acordada independentemente do assumir a responsabilidade real dos cuidados de que ela precisa no cotidiano, torna-se o signo não de uma igualdade entre os sexos, mas de uma não eqüidade e da negação da importância social do trabalho parental das mães. Mais ainda, alguns autores analisaram a reivindicação do compartilhamento da autoridade parental e da guarda compartilhada como uma tentativa dos homens em manter o controle e o poder sobre as mulheres após o divórcio, de conservar um direito de observar o cumprimento do trabalho maternal (Dufresne \& Palma, 2002).

Tratando-se de uma relação social que coloca em presença indivíduos e grupos em relação a seu lugar na divisão do trabalho e do poder, grupos ativos na definição das categorias sociais para pensar as divisões, por exemplo, na construção social das noções jurídicas, é normal surgirem de suas análises, fenômenos de resistência de uma e outra parte da relação. Como toda relação social, as relações sociais de sexo incluem uma luta incessante de dois grupos sociais agindo para melhorar suas situações respectivas e suas possibilidades de interferência sobre a evolução da sociedade, em seu favor.

\section{Conclusão}

A proposição do quadro teórico de análise das relações entre os sexos, feita neste artigo, visa superar o impasse metodológico no qual pesquisas sobre os homens e as mulheres podem encontrar-se fechadas quando querem hierarquizar níveis da realidade social. Os debates - franceses ou não - sobre as relações entre homens e 
mulheres e a divisão do trabalho entre os sexos estão plenos do desejo de compreender o que sobredetermina essas relações. A divisão do trabalho é o que rege o lugar social de homens e de mulheres, a inferiorização delas, a dificuldade delas de acesso ao poder, o retardamento de sua carreira profissional? Uma repartição mais igualitária do poder político entre os sexos não garantiria, ao contrário, uma divisão mais justa do trabalho e uma melhor responsabilidade pelos encargos com o trabalho de reprodução da vida humana entre homens e mulheres? Mas tudo isso não é, em última instância, uma questão de transformação das mentalidades e de hierarquias dos valores ligados às atividades femininas e masculinas? Os trabalhos empíricos que articulam as diferentes esferas da vida dos homens e das mulheres, considerando as evoluções sociais em termos de progresso ou regressão e que, enfim, integram a dimensão de luta entre os grupos de sexo permitem compreender que não há ordem prévia à construção dos sistemas de valores, divisão do trabalho e divisão do poder entre os sexos.

Anunciando as relações lógicas entre os diferentes modos de ação das relações sociais de sexo, sem hierarquizá-las teoricamente a priori, e oferecendo os instrumentos metodológicos para balizar essas relações sociais para todos os espaços em que elas se exercem, o quadro de análise proposto neste artigo me parece utilizável para se estudar as desigualdades entre os sexos, os fatores sociais que as produzem, sua evolução e suas interferências com outras relações sociais em diferentes sociedades - compreendidas aí aquelas que não repousam de modo prioritário sobre a economia salarial ou aquelas que parecem definir o lugar das mulheres primeiramente por divisões simbólicas.

\section{Notas}

1 E em outras regiões francofônicas, como o Québec.

2 No original: "cette réduction de l'identité sociale au pénis (ou non) est à chaque fois un acte social".

3 "Le genre precede donc le sexe". 
4 Na França, o serviço militar obrigatório foi abolido no início de 2000. Minha pesquisa foi feita entre 1990 e 1991, em cinco regimentos do Exército. Fiz mais de quarenta entrevistas. Busquei compreender, por um lado, porque alguns rapazes aceitavam prolongar a duração do serviço militar além do limite legal exigido; por outro lado, como a instituição formava esses jovens homens não somente do ponto de vista operacional, mas também no plano da socialização.

Abstract: The theory of social relationship between sexes: a panel about men domination

This article explains the french conceptualization of social relationship between sexes. It sets out the theoretical links between ways of action of this social relationship as gendered division of work, gendered division of power and gendered categorization on the one hand, and, on the other hand, its formal features: it has a crosssociety, dynamic and antagonistic action. Illustrations of these features are done through author's surveys of family, domestic work, army as well gendered memory. The article makes explicit the choice of the author to use the concept of "social relationship between sexes" rather than "gender".

Key words: social relationship between sexes, men domination, gendered categorization, sociological theory, epistemology.

\section{Referências bibliográficas}

BOURDIEU, Pierre. La domination masculine. Paris: Seuil, 1998.

DELPHY, Christine. L'ennemi principal. Partisans, n. 54-55, juillet-août, 1970. . L'ennemi principal. Tome 1 : Economie politique du patriarcat. Paris: Syllepse, 1998. (Collection Nouvelles Questions Féministes).

L'ennemi principal. Tome 2 : Penser le genre. Paris: Syllepse, 2001. (Collection Nouvelles Questions Féministes).

DEVREUX, Anne-Marie. La mémoire n'a pas de sexe. Pénélope, pour l'histoire des femmes, n. 12, p. 55-68, printemps, 1985.

. La double production: les conditions de vie professionnelle des femmes enceintes. Paris: CNRS, 1986. (Collection CSU). 
DEVREUX, Anne-Marie. Etre du bon côté. In: WELZER-LANG, Daniel; FILIOD, Jean-Paul. Des hommes et du masculin. Lyon: Presses Universitaires de Lyon et Bief-Cefup, 1992. p. 147-164.

. Des appelés, des armes et des femmes: l'apprentissage de la domination masculine à l'armée. Nouvelles Questions Féministes, v. 18, n. 3-4, p. 49-78, 1997.

Sociologie contemporaine et re-naturalisation du féminin. In: GARDEY, Delphine; LÖWY, Ilana (dir.). L'invention du naturel: les sciences et la fabrication du féminin et du masculin. Paris: Editions des Archives Contemporaines, 2000. p.125-135

. Du balai au fusil: l'apprentissage de la domination masculine à l'armée. In: BESSIN, Marc (dir.). Autopsie du service militaire 19652001. Paris: Editions Autrement, 2002. p.117-123. (Collection Mémoires, $\mathrm{n}^{\circ} 76$ ).

Autorité parentale: droits des pères et obligations des mères? Dialogue, 165, $3^{\text {ème }}$ trimestre, 2004.

DUFRESNE, Martin; PALMA, Hélène. Autorité parentale conjointe: le retour de la loi du père. Nouvelles Questions Féministes, v. 21, n. 2, p. 31-54, 2002.

FERMANIAN, Jean-David; LAGARDE, Sylvie. Les horaires de travail dans le couple. Economie et Statistique, n. 321-322, p. 89-110, 1998.

GODELIER, Maurice. L'idéel et le matériel. Paris: Fayard, 1984.

HALBWACHS, Maurice. Les cadres sociaux de la mémoire. Paris: Mouton, 1925. Edição utilizada: 1976.

HURTIG, Marie-Claude; PICHEVIN, Marie-France. La différence des sexes: questions de Psychologie. Paris: Tierce, Science, 1986.

KERGOAT, Danièle. Division sexuelle du travail et rapports sociaux de sexe. In: HIRATA, Helena; LABORIE, Françoise; LE DOARÉ, Hélène; SENOTIER Danièle. Dictionnaire critique du féminisme. Paris: PUF, 2000. p. 35-44. (Politique d'aujourd'hui).

SEXE du travail: structures familiales et système productif (Le). Grenoble: PUG, 1984.

McMAHON, Anthony. Taking care of men: sexual politics in the public mind. Cambridge University Press, 1999.

RIOT-SARCEY, Michèle. Le réel de l'utopie: essai sur le politique au XIX ème siècle. Paris: Albin Michel, 1998. 